\title{
Introduction of a web portal for an Individual Health Management and observational health data sciences
}

This article was published in the following Dove Press journal: Patient Related Outcome Measures

\author{
Dieter Melchart ${ }^{1,2}$ \\ Axel Eustachi' \\ Stephan Gronwald ${ }^{3}$ \\ Erich Wühr ${ }^{3}$ \\ Kristina Wifling' \\ Beatrice E Bachmeier ${ }^{1,4}$ \\ 'Competence Centre for \\ Complementary Medicine and \\ Naturopathy, Klinikum Rechts der \\ Isar, Technische Universität München, \\ Munich, Germany; ${ }^{2}$ Institute for \\ Complementary and Integrative \\ Medicine, University Hospital Zurich \\ and University of Zurich, Zurich, \\ Switzerland; ${ }^{3}$ Applied Health Care \\ Science, Deggendorf Institute of \\ Technology, Deggendorf, Germany; \\ ${ }^{4}$ Institute of Laboratory Medicine, \\ Ludwig-Maximilians-University, \\ Munich, Germany
}

Background: There is a global trend to a stronger active involvement of persons in the maintenance and restoring of health. The Competence Centre for Complementary Medicine and Naturopathy (CoCoNat) of the Technical University of Munich (TUM) has developed a lifestyle concept to enable each individual to manage his or her health - Individual Health Management (IHM) - and a web-based health portal named Virtual Tool for Education, Reporting, Information and Outcomes $\left(\right.$ VITERIO $\left.^{\circledR}\right)$, which addresses these needs for practice and research.

Objectives: The objectives of this study were to establish a core set of questionnaires for a self-assessment program on certain risk indications and comprehensive protection factors of health and to develop and enhance 1) tools for individual feedback, longitudinal self-monitoring, self-assessment, and (self-)care-planning; 2) training packages; 3 ) open notes and records for provider and patient; and 4) tools for monitoring groups and single participants in various indicators for individual coaching and scientific evaluation.

Methods: The CoCoNat of TUM, Faculty for Applied Health Science of Technische Hochschule Deggendorf, VITERIO ${ }^{\circledR}$ company, IHM campus network, and Erich Rothenfußer Foundation, Munich, provide a consortium responsible for content, research strategy, technical production and implication, postgraduate education for IHM coaches, implementation of IHM in various settings, and funding resources.

Results: A data set of indicators for health screening and self-monitoring of findings, symptoms, health behavior, and attitudes are integrated into a web-based health portal named VITERIO ${ }^{\mathbb{}}$. The article introduces some implemented graphical solutions of developed tools and gives examples for daily use.

Conclusion: Behavioral change and adaptation in attitudes and personal values are difficult issues of health education and lifestyle medicine. To address this problem best, the implementation of a patient-centric, performance measures-based program including open records and a blended learning concept were elaborated. The combination of an individual web-based health portal with personal coaching allows the implementation of IHM in everyday practice.

Keywords: lifestyle program, Individual Health Management, IHM, blended learning, performance measures, web-based health portal, adherence

\section{Introduction}

The prevalence of obesity and stress are continuously rising, and so related diseases such as type II diabetes and cardiovascular diseases have become a big issue for medical care and health systems.

Both conditions can be circumvented by prevention or intervention strategies such as lifestyle programs. ${ }^{1,2}$ These behavior change programs are based on the concepts of 
either "life counseling" where participants are trained and supervised by coaches ${ }^{3}$ or "quantifying self" where participants use tools to periodically measure their single body conditions. ${ }^{4}$ However, comprehensive programs combining both concepts are largely missing. Therefore, the sustainability of the achieved results remains a big challenge.

Poor accountability and adherence of individuals are well-known obstacles that account for failure and lacking benefits of preventive and therapeutic lifestyle recommendation programs. ${ }^{5,6}$ One of the problems here is that participants of such medical programs have only very restricted possibilities to monitor their personal progress during the course of the program either because they are not trained well enough for collecting their personal data indicating their personal progress or due to a lack of a tool to generate numeric or other measurable outcome data. Usually, measurable data are obtained only at the end of the program, such as in weight-reducing programs or diabetes prevention strategies. In order to enhance the accountability and adherence of the clients and patients, it is therefore recommended to conceptualize various performance measures (PMs) that enable them to participate and engage their trainings and treatment plans. ${ }^{7}$

The Competence Centre for Complementary Medicine and Naturopathy (CoCoNat) located in the Medical Faculty of the Technical University of Munich (TUM), Germany, has been developing an applicable approach to measure patient-reported outcomes (PROs) for the needs of clinical and outcomes research, health education, and everyday practice in the field of Traditional Chinese Medicine (TCM), kneippism, and behavioral change programs.

In the last 10 years, CoCoNat has been generating an Individual Health Management (IHM) that enables the individual to care for and optimize his or her own so-called physiological basis functions as well as psychosocial and cognitive basis competences during daily life combining "life counseling" with "personal coaching." 8

The use of organismic, psychosocial as well as cognitive personal contributions to stay healthy is a core issue of salutogenic theory and of many of the folk medicines.

Physiological basis functions are important control paths and processes of body health such as breathing, exercising, nutrition, neurovegetative balance, immunological resistance, thermoregulation, sleep, and biorhythm. Psychosocial and cognitive basis competences are focusing on self-competence in, e.g., successful regulation processes of negative emotions and interpersonal skills. ${ }^{8}$
The IHM is a lifestyle concept aimed at the early detection, avoidance, and self-treatment of cardiovascular, metabolic, and stress illnesses. Oriented on the salutogenic model and theory of a health-ilness continuum, the IHM is directed at both "healthy" and "ill" people with the goal of strengthening their self-determination, self-competence, and own responsibility in both sickness and health. It is supporting patient's self-management when suffering already on chronic diseases of different etiological factors. The IHM program is based on empirical findings of stress management, self-help techniques, and behavioral change. It has been designed as a "blended learning" program. "Blended learning" means the mixing and linking of modern e-health technologies with traditional personally attended lessons or counseling. ${ }^{9}$

Further, in order to bear responsibility for oneself and to realize any self-management, it is also necessary to possess full medical information about oneself. That means there is a need to share all notes and records, which have ever been documented by the providers, between client and patient. With this, an attempt has been made to cope with the problems of the lack of sustainability and pedagogical mediation by directing toward coaching. It is created to achieve lifestyle modification with the combined help of personal coaching and the electronic health portal named Virtual Tool for Education, Reporting, Information and Outcomes $\left(\right.$ VITERIO $\left.^{\circledR}\right)$. VITERIO ${ }^{\circledR}$ represents the technical background of the IHM lifestyle program. These on-site computer and web technologies made it possible to measure PROs in web users and study participants within a wide range of health promotion and chronic diseases. ${ }^{10,11}$ Subjective experiences such as symptom severity and frequency, well-being, and perceived level of functional ability are various aspects of PROs. Hence, this system is useful in clinical practice to assess response to interventions and training plans, to give feedback to the users as supplied support strategy, and to evaluate issues of perceived effectiveness, efficacy, safety, costs, and adherence. In addition, individual health data from outside the IHM program comprising blood counts, vaccination/immunization status, and doctor's reports can be included into VITERIO ${ }^{\circledR}$. Users can determine themselves whether to pass these data to health professionals. Thus, VITERIO $^{\circledR}$ can be used as central data collection comprising all available health-illness data for every single user. This article describes the developmental work of VITERIO ${ }^{\circledR}$ and demonstrates some important prepared features derived from predefined objectives. 


\section{Objectives}

Following research objectives were specified:

- To establish a web-based health portal including a core set of scientifically substantiated questionnaires, which will address the most common dimensions of self-reported data, PMs, and outcomes of physiological basis functions and cognitive-psychosocial basis competences of the IHM concept.

- To develop a tool for analyzing, monitoring, and coaching of groups and single participants in various indications of distant lifestyle counseling or clinical trials.

- To develop and enhance important technical tools for feedback, longitudinal self-monitoring, self-assessment, and (self-) care-planning.

- To develop and enhance training packages for IHM.

- To develop and enhance open notes and records for both provider and patient.

- To define a concept to user's privacy.

\section{Methods}

\section{Involved institutions and responsibilities for research strategy and technical development}

CoCoNat is the principle investigator of IHM and VITERIO ${ }^{8}$ and responsible for the implementation and adaptation of the software platform. VITERIO ${ }^{\circledR}$ is part of a blended learning system that combines an individual care and group support with a tailored web-based program to achieve the desired goals. The competence center also cares - in collaboration with the Faculty for Applied Health Science, Deggendorf for the train-the-trainer concept. It should qualify health professionals to IHM coaches. These interventionists assist participants, e.g., in adhering to a lower-calorie diet and in increasing physical activity within their high-intensity comprehensive weight loss interventions $(\geq 15$ sessions $=60$ hours in 12 months) provided in individual or group sessions.

The technical partner of VITERIO ${ }^{\circledR}$, a company with the same name, is responsible for the operability of the portal. The company is owned by the nonprofit foundation "Erich Rothenfußer Stiftung," Munich, and responsible for the technical realization of the project. The web-platform, mostly - but not only - used for the implementation of the lifestyle program IHM, gives technical support to clients and patients helping them to put the program into practice. All partners provide a consortium, called IHM campus, responsible for content, research strategy, technical production and implication, postgraduate education for IHM coaches, and funding resources (www.igm-campus.de).

\section{PRO measures (PROMs)}

PROs are findings that reflect the subjective sensation of an individual person concerning his or her quality of life, health status, moods or emotions, attitude, behavior pattern, and so on. PROs are collected in numerous questionnaires ranking from high-quality evidence-based and validated forms to simple nonvalidated feedbacks. PROMs are an important tool to analyze and modify one's attitude and behavior patterns in order to enhance the health level. The perceived assessment of health, illness, and benefits of prevention measures and health care interventions from the patient's perspective becomes more and more important nowadays.

Through systematic self-logging, the participant gets an overview over his or her own basis functions and basis competences that serve as a reference in comparison with a group or to oneself in the course of a lifestyle modification program.

Health-related quality of life, subjective health status, and perceived state of body, mind, and mood are important measures in autonomous therapy as practiced in complementary and preventive medicine and are also used as primary or secondary end points in clinical trials.

The Health Check in VITERIO ${ }^{\circledR}$ is based on a core set of scientific and evidence-based questionnaires for PROs. All questions and their analysis are oriented toward an idea to give an overview of individual risk factors and protection factors to the user. The corresponding items should demonstrate a "risk protection ratio," highlighting cardiovascular and metabolic, neurovegetative, and mental risk factors, on the one hand, and life satisfaction as well as other protection factors according to the theory of basic functions and basic competences, on the other hand.

\section{VITERIO ${ }^{\circledR}$}

The health portal VITERIO ${ }^{\circledR}$ is a web-based tool that was designed to collect PROs and to make them available in equal measure for the participant (Patient-Reported Outcomes, Measurement and Information [PROMI] system) and the health professional (Provider Reported Outcomes of Findings and Interventions [PROFI]) throughout the course of clinical studies/trials or lifestyle modification programs such as the IHM. VITERIO ${ }^{\circledR}$ represents the technical background of the IHM lifestyle program. Background theories are, among others, the systemic requirement and resource 
model, the balance of conflict model, the training of emotional competences according to Berking, the model of systematic self-observation of health behavior according to Ellis, and also rational-emotive behavior therapy. ${ }^{12,13}$ On the basis of theses background theories, scientifically evidence-based questionnaires are included in VITERIO $^{\circledR}$ which have to be completed by the participants. Specific algorithms have been designed for the evaluation of the questionnaires and serve as basis for the Health Report created by VITERIO ${ }^{\circledR}$ in case the participant has completed the periodical Health Checks. The Health Check is the systemic perception of health-related risk and protective factors with the assistance of VITERIO ${ }^{\circledR}$. Each participant learns to monitor his or her attitudes and behavior change during daily life and to record symptoms during illness. The task of documentation and recording as hard copies and online is supported by systematic feedbacks in the form of reports, graphical elements, and personal consultation.

The participant adds his or her personal health data, standardized measurements (e.g., blood pressure [BP], waist circumference, and body mass index [BMI]), and doctor's reports along with the subjective impressions of discomfort as well as mental and mood state into the web-based questionnaires.

As a result, the participant develops awareness of his or her attitude and behavior patterns and the proper health risk and determines his or her position in life and personal satisfaction level.

Numerous features (e.g., diaries, "Info@zepte”) help each participant or patient to implement a self-determined and healthy lifestyle. This concept enhances adherence of the participants to lifestyle modification programs.

VITERIO $^{\circledR}$ creates a written Health Report in form of a "PDF file" based on personal risk factors and protection factors. Within this health-plan, the results are illustrated in the form of circle and in the colors of a classic traffic light with green indicating no risk, yellow a medium risk, and red a high risk. In this traffic light chart, individual risk factors are opposed to protection factors (see "Result" section). In addition, the Health Reports illustrates the individual life satisfaction and gives early health warnings that indicate possible risks for the development of lifestyle diseases. A separate section of the Health Report is dedicated to the individual risk for developing type II diabetes, hypertension, and global cardiovascular risks for cardiac infarction and stroke.

Along with the trimestral Health Checks, the respective Health Report updates the personal risk group, and the program provides tailored information on healthy lifestyle due to the individual risk indication with the help of web-based training packages.

\section{IHM program}

The general strategy of the program is to determine the individual health risks such as diabetes and cardiovascular diseases by analyzing each participant's sociodemographic data along with standardized measurements of body weight, size (BMI calculation), waist circumference, and BP. All these measurable and data are collected by questionnaires that are part of the web-based tool VITERIO ${ }^{\circledR}$ and contain information on the participant's perceived physical and mental states as well as objective medical data (e.g., laboratory parameters). Goal is to optimize the participant's lifestyle in order to prevent obesity- and stress-related diseases; thus, each participant shall achieve a longer healthier life with more life satisfaction.

In order to optimize adherence of the participants, the IHM program is based on a blended learning concept combining the systematic self-observation, self-perception, and self-reflection of one's own symptoms and signs of health and illness with the web-based VITERIO ${ }^{\circledR}$ screening tool and lifestyle counseling with specially trained IHM coaches. The basic concept of IHM is "Health Check - plan - act" and consists of a 12-week basic training program and a minimum of a 9-month buildup or maintenance phase. Within the "Health Check" - phase of IHM, two different Health Checks are performed with a core set of questionnaires for self-reported data, routinely. Reexamination is realized every 3 months. The VITERIO ${ }^{\circledR}$ web portal fulfills the needs of the IHM program, and the runtime is at least 1 year. Prolongation of the program and access to VITERIO ${ }^{\circledR}$ are possible by request.

All aspects of IHM are mirrored in the VITERIO ${ }^{\circledR}$ website's menus including instructions, schedules, logbooks, audios, videos, and written information (Info@zepte ${ }^{\mathbb{R}}$ ) that contain the core messages in a concise and easy-to-read language. The IHM is timely and in form, and content was structured into a "screening program" (life satisfaction and health risk awareness), "introduction program" (including in-depth health risk factors and protection factors analysis, medical checkup, and presentation of the program), "everyday program" (3 months, from 10-12 after-work group sessions), and the "maintenance program" ( 9 months, monitoring of health parameters, motivational refresher meetings, and medical checkups). ${ }^{8}$

\section{Clinical trials}

To date, VITERIO ${ }^{\circledR}$ was used in a multicenter randomized controlled trial assessing the impact of tailored lifestyle self-management intervention (TALENT) study on weight reduction. ${ }^{10,11}$ Further clinical studies are in preparation. The TALENT study was designed to examine whether an IHM with a blended learning concept combining self-observation, 
along with lifestyle counseling and medical consultations, ${ }^{8}$ can improve adherence to a lifestyle intervention program on weight reduction resulting in better outcomes. Adherence of participants and behavioral change should be promoted by various forms of group sessions, physician-led counseling, self-tracking, and self-determination using the health portal VITERIO $^{\circledR}$. The two main phases of the TALENT study were a 3-month weight reduction phase (in exceptional cases up to 6 months) and a 9-month maintenance phase. Throughout both phases, participants used VITERIO ${ }^{\circledR}$, to protocol the course of their health data concerning measurable parameters such as weight, BMI, BP, and perceived parameters like mood; thus, VITERIO ${ }^{\circledR}$ represents an excellent tool for maximum transparency of study results at any time throughout the duration of the clinical trial for both sides, the participant and the physician. In addition, VITERIO ${ }^{\circledR}$ provides the participant with detailed advice and instructions with respect to food, exercise, relaxation, and various other indicators.

\section{Results}

\section{Core set of questionnaires for self- reported data in Health Checks I and 2 of VITERIO ${ }^{\circledR}$}

On the welcome page, the VITERIO ${ }^{\circledR}$ health portal starts with a selection tool that consists of the three parts of the basic concept of the IHM: check (orange 1) - plan (blue 2) - act (green 3) (Figure 1).
At the very beginning of the IHM program, the user performs "Health Check 1," in order to prove cardiovascular and metabolic risks for hypertension, diabetes mellitus, overweight, and stress-related disorders. Health Check 1 uses the following core set of physical data and questionnaires (Table 1): body weight, body height, waist circumference, systolic and diastolic BP, risk assessment on hypertension (Framingham), diabetes (Finnish Diabetes Risk Score [FINDRISK]), and burnout (Tedium Measure). ${ }^{14-16}$ The Framingham hypertension risk score provides a simple and valid tool with which to estimate near-term risk of developing hypertension including only seven items: age, sex, systolic and diastolic BP, BMI, parental hypertension, and cigarette smoking. ${ }^{17}$ The questionnaire FINDRISK identifies individual risks of developing a type II diabetes mellitus within the next 10 years. ${ }^{18}$ Obesity together with elevated waist circumference accounts for one third of the total risk in FINDRISK. The Tedium Measure is a questionnaire that consists of 21 items that express exhaustion and that are scored on a 7-point rating scale, ranging from "never" to "always." 16

In addition to the questionnaires, the user is motivated to document a short structured medical history, biographical history, and comprehensive medical history. Finally, this examination ends with a questionnaire for life satisfaction (Fragen zur Lebenszufriedenheit [FLZ]), one of the most important protection factors of human beings. ${ }^{19}$ The FLZ presents a questionnaire for assessing general and healthrelated quality of life. It combines three features: economy,

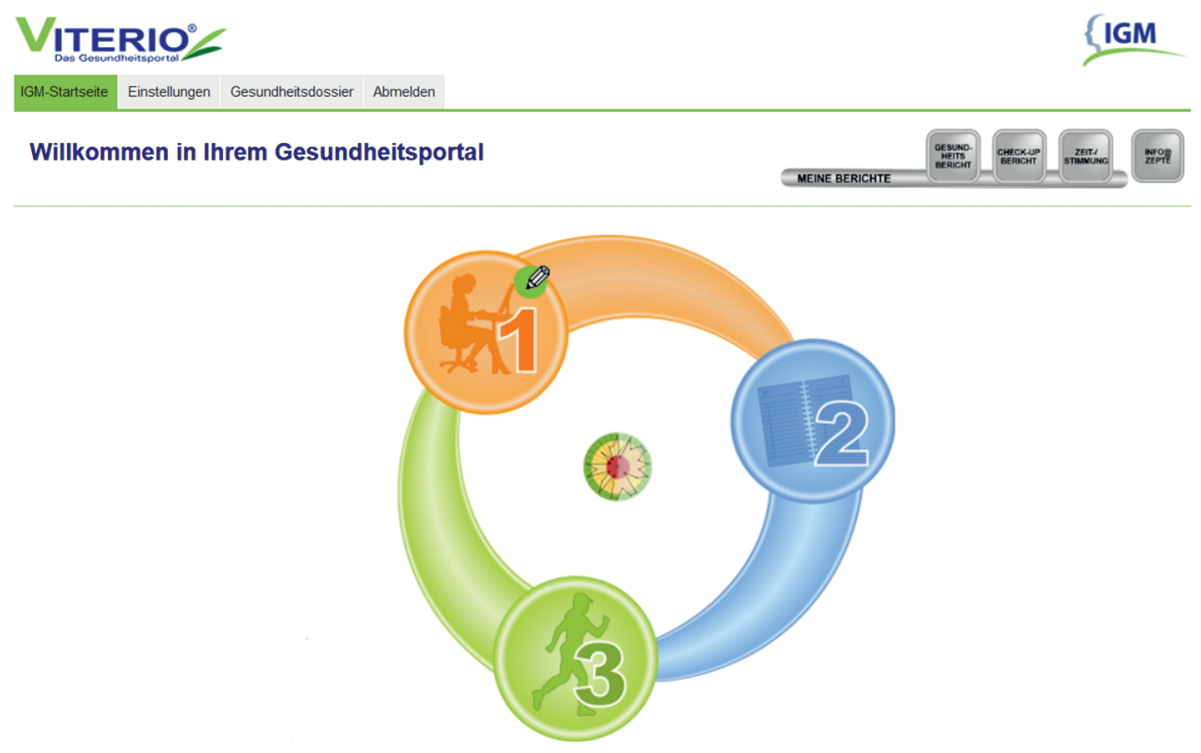

Figure I Welcome page.

Notes: orange I = check; blue 2 = plan; green 3 = act. 
Table I Questionnaire for Health Check I (trimestrial)

\begin{tabular}{|l|}
\hline Health Check I \\
\hline Socio-economic and demographic variables \\
\hline Biographical history \\
\hline Comprehensive medical history \\
\hline Physical data: self-reported body height, body weight, \\
waist circumference \\
\hline Systolic and diastolic blood pressure \\
\hline Risk assessment on hypertension (Framingham) \\
\hline Risk assessment on diabetes mellitus (FINDRISK) \\
\hline Risk assessment on burnout (Tedium Measure) \\
\hline Short structured medical history \\
\hline Motivation \\
\hline Life satisfaction
\end{tabular}

Abbreviations: FINDRISK, Finnish Diabetes Risk Score; IHM, Individual Health Management.

modular structure, and individual weighting of items. It consists of two 8-item modules: "General Life Satisfaction" and "Satisfaction with Health."

An algorithm of these self-reported data identifies different risk indications: free of any tested risks, overweight (light, moderate, heavy, and morbid), prehypertension, hypertension, prediabetes, diabetes, preburnout, burnout, and smoking cessation. Depending on the risk group, the program provides appropriate training plans and training packages for IHM in the "health plan" and "health act" of VITERIO ${ }^{\circledR 8}$.

Within "Health Check 2," the participant defines one's personal position: What worries me? Which consequences did these kind of stress already trigger in me? Which protective factors do I have? A systematic ascertainment of worldwide cardiovascular risks, stress factors, neurovegetative stress reactions, addictive factors (tobacco and alcohol), physical and psychosocial protective factors with regard to exercise and nutritional behavior, resistance, sleep, health competence, and social competence forms the core set of Health Check 2 (Table 2): The World Health Organization (WHO)-Five Wellbeing Scale (WHO-5) is a short and generic global rating scale measuring subjective well-being. The WHO-5 items are the following: 1) "I have felt cheerful and in good spirits." 2) "I have felt calm and relaxed." 3) "I have felt active and vigorous." 4) "I woke up feeling fresh and rested." and 5) "My daily life has been filled with things that interest me." ${ }^{20,21}$ The questionnaire for self-efficacy, optimism, and pessimism represents a valuable tool in the context of therapeutic indication prognosis and outcome evaluation. ${ }^{22}$ The concept of "sense of
Table 2 Questionnaire for Health Check 2 (trimestrial)

\begin{tabular}{|l|}
\hline Health Check 2 \\
\hline Severity of mood state in general (VAS) \\
\hline Psych-vegetative test \\
\hline Thermoregulation, sleep \\
\hline The body's defences \\
\hline Vitality, wellbeing (WHO-5) \\
\hline Stresses and strains (Perceived Stress Questionnaire) \\
\hline Pessimism (SWOP) \\
\hline Smoker questionnaire, tobacco addiction (Fagerström) \\
\hline Alcohol (number of drinks, CAGE test) \\
\hline Subjective depressive mood \\
\hline Cardiovascular and metabolic risk factors \\
\hline Laboratory data (total cholesterol, TG, LDL, CRP) \\
\hline PROCAM risk score \\
\hline Nutrition index \\
\hline 5-a-day monitoring \\
\hline Weblog \\
\hline Physical power in MET \\
\hline Moving index \\
\hline minutes / 2 km walking test \\
\hline
\end{tabular}

Abbreviations: CRP, C-reactive protein; IHM, Individual Health Management; LDL, low-density lipoprotein; MET, metabolic equivalent; PROCAM, Prospective Cardiovascular Munster; SWOP, self-efficacy, optism, pessimism [selbstwirksamkeit, optimismus, pessimismus]; TG, triglyceride; VAS, visual analog scale; WHO-5, World Health Organization (WHO)-Five Well-being Scale.

coherence" (SOC) was put forward by Antonovsky to explain why some people become ill under stress and others stay healthy. The SOC is defined as "the extent to which one has a pervasive, enduring though dynamic, feeling of confidence that one's environment is predictable and that things will work out as well as can reasonably be expected." Versions of the questionnaire have been used worldwide in many countries. ${ }^{23}$ The Perceived Stress Questionnaire (PSQ) in Health Check 2 was developed by Levenstein et $\mathrm{a}^{24}$ and modified by Fliege et $\mathrm{al},{ }^{25}$ to measure stress levels. The PSQ is proven to be superior to alternative measures for predicting stress-related health outcomes, because of its high consistency, high reliability, and 
validity. The Fagerstrom Tolerance Questionnaire is a test to evaluate nicotine dependence. ${ }^{26}$ The Medical Outcomes Study (MOS) Social Support Survey is a 19-item, self-administered survey developed for patients in the MOS. ${ }^{27,28}$ It was originally designed as a self-administered measure of functional social support in community-dwelling chronically ill persons. As part of the MOS, a multiyear, multisite study to explain variations in patient outcomes, Research and Development Corporation developed the 36-item Short Form (SF-36) Health Survey. SF-36 is a set of generic, coherent, and easily administered quality of life measures. ${ }^{29,30}$ The Prospective Cardiovascular Münster Study risk score predicts the probability to suffer from a myocardial infarction in the next 10 years. ${ }^{31}$ Questionnaires on physical activity, metabolic equivalent values, as well as nutrition index were developed in-house.

Beside this core set of questions determining the individual risks in both Health Checks, various other questionnaires, addressing individually these findings, can be added and tailored to different issues by health professionals, health coaches, or clinical researchers.

Both Health Checks provide a systematic perception of health-related risk factors and protective factors (Figure 2A) with the assistance of web-based tools and facilities. It also helps the user to monitor results and behavior during daily life and to record symptoms during illness. In addition, results from blood counts and other objectively measurable health data can be added. Feedback is given in the form of dynamic Health Reports with detailed information about the risk and protective factors, constantly available as a PDF file (Figure 2A).

\section{Tools for longitudinal self-monitoring}

Besides creating the dynamic Health Report reflecting the participant's status quo and change in risk and protective factors, VITERIO ${ }^{\circledR}$ provides these results graphically in the form of a circular chart in traffic light colors. This figure represents different risk factors and protection factors and gives an overview to the user enabling her or him to identify easily which indicators need to be changed (Figure 2B). Thus, priorities for training plans in terms of content, intensity, and time line can be set, making it easy for the participants to decide the appropriate measures. The complete data set is also available for the medical doctor or coach on the respective PROFI site of VITERIO ${ }^{\circledR}$. Thus, the participant has the possibility to discuss appropriate measures for lifestyle modifications with a trained and experienced health professional.

Self-awareness and systematic self-monitoring might support adherence to lifestyle change. ${ }^{32,33}$ Therefore, each participant is equipped with a starter kit containing self-

A

Your diabetes risk

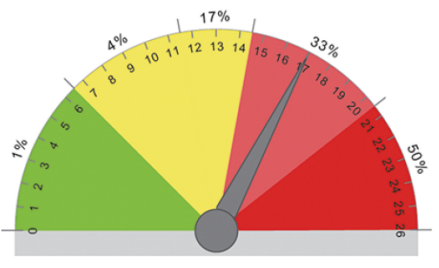

$33 \%$ (17 points)

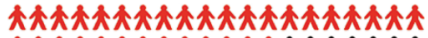

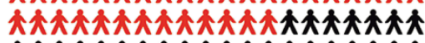

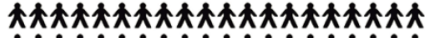

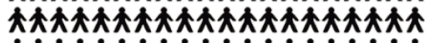

Risk of developing type 2 diabetes mellitus in the next 10 years: $33 \%$

B
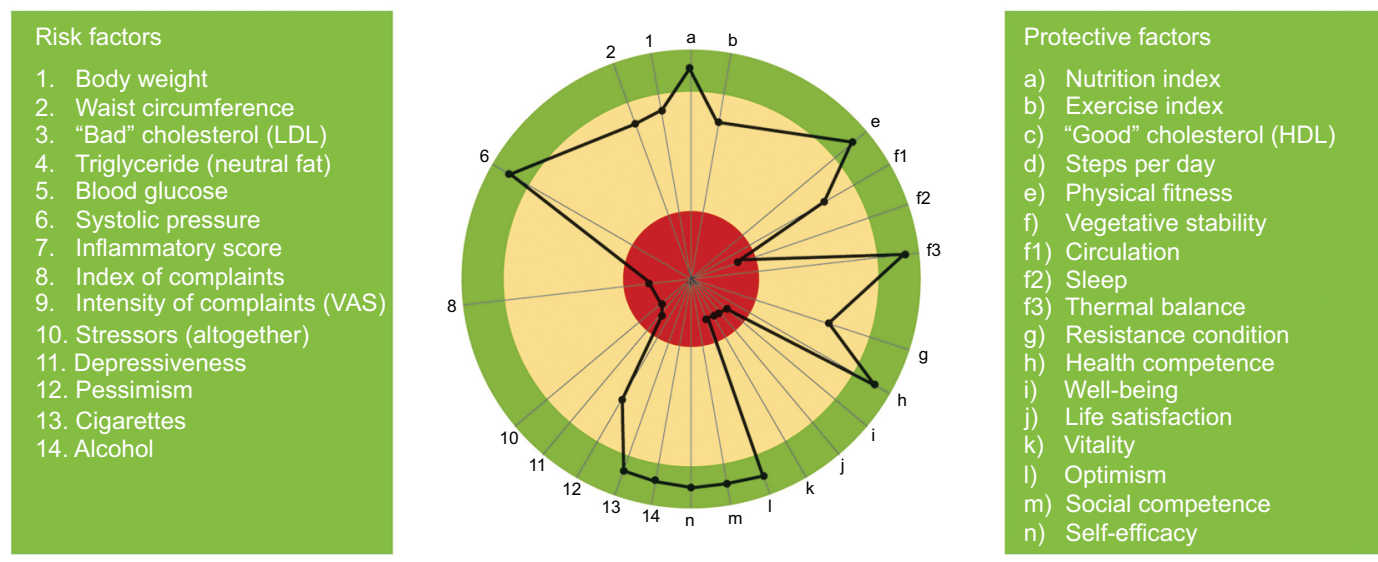

Figure 2 (A) Individual diabetes risk and (B) protection factors.

Abbreviations: HDL, high-density lipoprotein; LDL, low-density lipoprotein; VAS, visual analog scale. 
monitoring tools such as a pedometer, visual analog scale (VAS), and waistband. Participants are instructed how to use the tools by hands-on teaching. To assess physical capacity, participants perform a 6-minute or 2-km walking test. ${ }^{34} \mathrm{~A}$ Borg scale rates the perceived exertion. ${ }^{35}$

A 7-day self-monitoring protocol as supplied in VITERIO $^{\circledR}$ serves to analyze everyday behavior and physical findings and to record the participant's daily amount of steps and proportions of healthy food, symptom severity or mood state, weight, waist circumference, and BP. The PROs are documented on a paper-based form and transferred later into the online portal or, instead of this, directly into VITERIO $^{\circledR}$. During a weight loss program, participants are advised, e.g., to record daily a set of measures such as steps and body weight.

To assess daily activities and associated moods, the authors developed a time and mood analysis protocol, which has to be completed by each participant during the introduction program and continuously before starting the refresher meetings. The protocol addresses the time spent (in minutes) on specific private or occupational activities (e.g., leisure time, eating, and organizing meetings) as well as the associated mood, measured with VAS.

Participants insert their data autonomously into the web portal, and the software and algorithms create mood diagrams or pie charts. This tool promotes the participant in stocktaking of oneself, and the diagrams help to figure out which areas to address first for the desired behavioral change. This is accompanied by weekly training plans, various individual health-supporting offers such as specific health days, practical workshops, and personal coaching also in the form of a distant lifestyle counseling (Figure 3).

\section{Open notes and record data}

Within a third step of the Health Check phase of the IHM program, physicians serve a medical-psychological checkup (Health Check 3). The outcomes of the physical examination and laboratory data are directly completed into the web portal by the physician or his/her assistance. This checkup creates an electronic health history, vaccination health record, biographical health record, and emergency data in the sense of the European data record (e-Health). Report and checkup results are available as hard copies and electronically. Technically, this has been realized by developing two corresponding entry masks - one for patients (PROMI) and the other for providers (PROFI; see also Figure 4).

This bidirectional data flow makes it possible to inform physicians as well as coaches about PMs from everyday life
Training packages

Self observation: time-mood-analysis, observation of results, behavior and attitude during daily life, self perception.

Exercise: supporting of daily exercise, stamina exercise, strength, coordination.

Nutrition: 10 rules for daily healthy eating, rules for doing without, days with reductions, days of fasting, exchange of oil, dietary supplements.

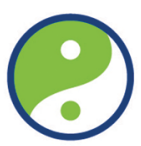

Stress management: identification and alteration of stress factors, muscle and respiratory relaxation, Qi-Gong, self effectiveness exercises, well-being, rational emotional behavior, recognition of values and goals.

Remedies and natural substances: among other things, water and thermal application, plant and natural remedies, massages, acupressure

Figure 3 Training packages.

VITERIO- Virtual Tool for Education, Reporting, Information and Outcome (web-based health portal)
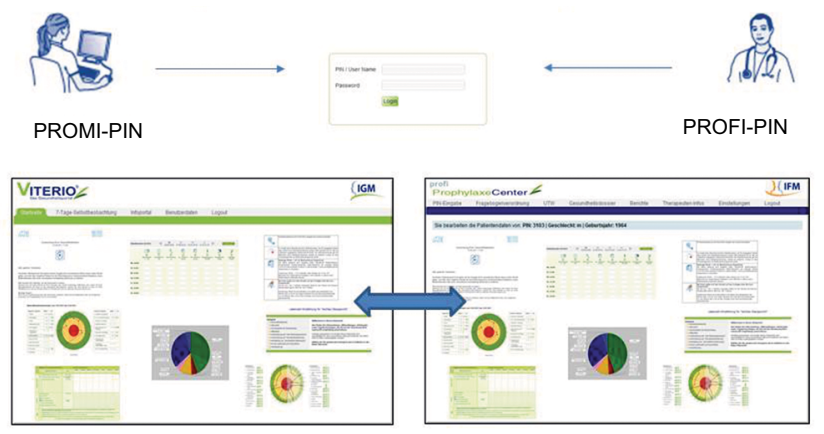

Patient education - Quality assurance - Electronic clinical research

Figure 4 Development of entry masks.

Abbreviations: PROMI, Patient-Reported Outcomes, Measurement and Information; PROFI, Provider Reported Outcomes of Findings and Interventions.

of the clients/patients; the other way round, the providers allocate their notes of medical data such as findings, diagnoses, interventions, and information as to biographical-medical history to the clients and patients. These open notes and structured data of medical records are available simultaneously and just in time for both sites after completion and saving. ${ }^{36}$ The e-Health dossier created by VITERIO ${ }^{\circledR}$ compiles all these individual data, available also as a hard copy for offline use. 


\section{Tool for group and single monitoring}

The IHM is a lifestyle program designed for coaching individuals and groups. Technical support in monitoring participants during their course of behavioral change and maintenance phase is an essential measure for the coaches in order to give personal advice and to increase the adherence of the participants. VITERIO ${ }^{\circledR}$ offers the technical prerequisite for distant lifestyle counseling by providing a platform where the entire information, collected by VoIP, e-mail, phone, fax, or face-to-face meetings, flows together. We developed a tool for group monitoring enabling coaches to evaluate change in behavior, findings, and special indicators on the PROFI site of VITERIO ${ }^{\circledR}$. Monitoring up to 15 single graphs of group members simultaneously on the display is reasonable (Figure 5). Further, in order to monitor and to coach a single person, it is necessary to have the course of a single indicator of one participant (Figure 6).

\section{Training packages for IHM}

Parts 2 (plan) and 3 (act) of the selection tool on the VITERIO ${ }^{\circledR}$ welcome page offer an overview and access to all training packages. They comprise the sections "self-observation,"

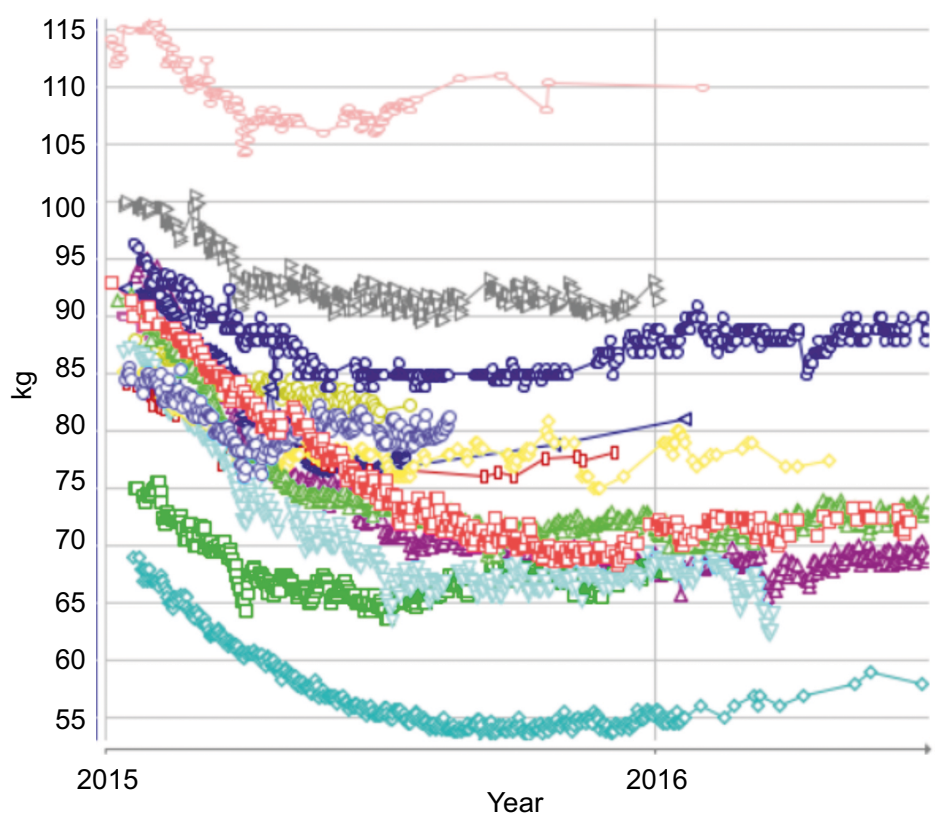

Figure 5 Single graph of group members.

Notes: Every single curve represents one single group member. Data for weight loss of each single group member were collected between $2015-2016$.

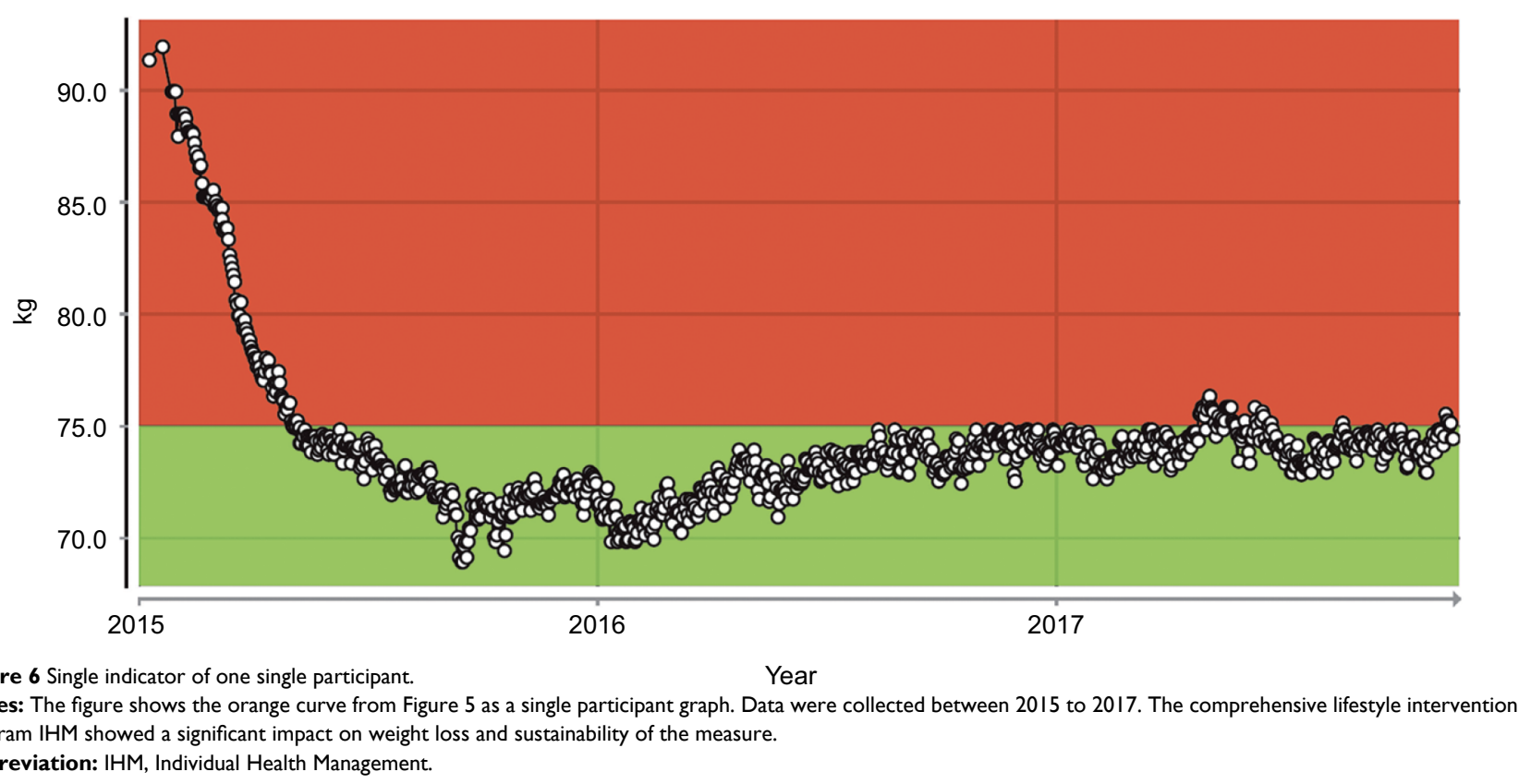


"exercise," "nutrition," "stress management," and "remedies and natural substances." Depending on the defined risk group, determined by the Health Check 1, the program offers schemes of training plans as well as tailored information on healthy lifestyle with the help of web-based training packages.

Each section is equipped with detailed information in the form of Info@zepte and provides the participant with comprehensive advice how to modify his or her lifestyle. Furthermore, one section of the training plan and package is designed to provide an individual summary and Info@ zepte, which are tailored by the health professional, coach, or the user himself or herself to the needs of the participants. In addition, there are other important health issues such as organ donation, vaccinations, and early detection examinations for an individual health planning.

\section{Tool for clinical trials}

VITERIO $^{\circledR}$ has already been used for the TALENT study where the effect of a tailored lifestyle intervention on weight reduction has been analyzed. ${ }^{11}$ Especially for this study, the web-based health portal was an ideal tool to monitor health establishment of each participant and, throughout the course of the study, modifications in lifestyle and their direct impact on weight loss and well-being. In this context, all the participants received tailored advice in the form of audio files, video files,

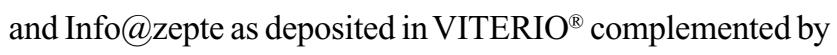
(distant) lifestyle counseling by coaches and health professionals. This concept of "blended learning" increased adherence to lifestyle modifications and thereby positive outcomes. The main outcome parameter "body weight" showed a mean decrease of $8.7 \mathrm{~kg}(\mathrm{SD}=6.1, \mathrm{n}=109)$ in the intervention group (IHM) and $4.2 \mathrm{~kg}(\mathrm{SD}=5, \mathrm{n}=57)$ in the control group after 12 months. General linear model testing of the change values revealed a highly significant difference between the groups ( $p<0.001, t$-test for paired groups). In addition, it was shown that, in both groups, the respective weight reduction from month 0 to month 12 was statistically significant $(p<0.001)$; $66 \%$ of the participants in the IHM group showed a weight reduction of at least $7.5 \%$ of baseline value at month 12 , while only $13.3 \%$ of the participants in the control group fulfilled this criterion. This difference proved to be statistically significant ( $p<0.001$, Fisher's exact test).

Along with the weight reduction, secondary variables such as BP, fasting sugar, and low-density lipoprotein cholesterol were significantly reduced. Findings from a further secondary analysis indicated an association between the level of self-monitoring of daily lifestyle and weight loss. ${ }^{11}$

\section{Data security concept}

An increasing amount of personal health information is being collected and stored in a repository and database at the TUM. This induces the need for a data security concept protecting the confidentiality and security of all web users. First, all data are documented in the central database without personal information. The only personal data permitted are sex and age in years. Various personal identification number administrations obtaining corresponding personal identification data are merely available at individual providers within the network of IHM campus. Thus, the data architecture is distributed and not centrally organized. Most of the administration software is running on standalone computers of outdoor practices, prevention centers, day clinics, and hospitals. Clients and patients organize data access to VITERIO $^{\circledR}$ by means of an own administration. They decide who is authorized to have a look at it or not, exclusively. Each user is responsible for the accuracy and completeness of the submitted information. For all information such as PMs, laboratory test results, and results of medical findings filled in - independently by whom - there is a detailed time stamp for each activity and a registry of an authentication code. Furthermore, a written agreement regulates access to clinical trial data for reanalysis or secondary scientific research for observational study data.

The most important characteristics concerning the data security concept are as follows:

\section{Anonymity}

- No personalized data will be collected.

- No registration of personal data such as name, address, and bank details.

- The collected medical data do not allow any conclusion on distinct persons.

- No data storage regarding IP addresses of hosts.

\section{Trust center}

- Data storage at the CoCoNat, which is part of the TUM.

- CoCoNat serves as a trust center.

- No commercial exploitation of data.

- Exemption from attachment of wages for all data.

Secure Sockets Layer (SSL) encryption

- Data transfer via SSL encryption.

- Advanced Encryption Standard 256-bit standard encryption 


\section{Discussion}

Biomedical outcomes such as clinical and laboratory parameters used in modern academic medicine need to be complemented by measures that focus on the patient's concerns in order to evaluate interventions and identify more appropriate forms of health care. ${ }^{37}$ In the assessment of health, illness, and therapy success, PROs are important measures, because they reflect the perspective of the patient, which eventually cannot be captured in clinical dimensions; however, the perceived well-being and quality of life are equally important for the patient for objectively measurable therapy success (e.g., surgical removal or minimizing of tumor burdens).

Learning self-management and self-help within a framework of a lifestyle or a chronic diseases management program supports clients and patients in health literacy, selfcompetence, and participation. ${ }^{38,39}$ However, this approach is a big challenge for client, patient, and coaches involved equally in this process.

A big issue in this process is intermediation of teaching and learning contents, which we addressed in particular within the implementation phase of our lifestyle modification program IHM. Blended learning and giving feedback by PMs are the most important features to evaluate and to teach the course of change in behavior and mind. Weight control, self-motivation in physical exercise, and control in emotional management are examples for self-monitoring and learning of important competences to keep oneself healthy in daily life. ${ }^{40}$ Final goal is to achieve a better maintenance and adherence of participants toward the IHM program. ${ }^{40,41}$

The central element of IHM is a form of self-management, which provides the individual with the ability to take care of and optimize his or her basis functions (exercise, nutrition, vegetative balance, resistance, thermal balance, sleep, and rhythm) and psychological and cognitive basis competences (stress management, communication, self-efficacy, sense and value orientation, well-being, self-perception, and self-reflection) in everyday life, with the objective of sustainably increasing, maintaining, or restoring his or her personal quality of life and life satisfaction through a healthy lifestyle. This concept gave orientation in finding the suitable items and dimensions for monitoring the participants' risk factors and protection factors for health. Related to these factors, adequate questionnaires had to be found and proved to be correct and valid for this purpose. In addition, all questionnaires had to be free of license fee. These questionnaires exert the basis for the web-based health portal VITERIO $^{\circledR}$ that was designed to collect PROs and to make them equal measures available for the participant (PROMI) and the health professional (PROFI) throughout the course of clinical studies/trials or lifestyle modification programs such as the IHM. PROs are an important method to capture the subjectiveness of a person's attitude and behavior. This is of utmost importance in complementary medicine where the autonomous performance of the patient comes to the fore. In this way, VITERIO ${ }^{\circledR}$ becomes an important tool to map participant's personal contribution and responsiveness. VITERIO $^{\circledR}$ thereby serves as a tool for systemically monitoring and managing individual risk factors and protection factors and in case of need for documentation of indications and symptoms. In addition, numerous features (e.g., diaries and Info@zepte) help the participant to implement a healthy lifestyle and facilitate informational self-determination.

A predecessor of VITERIO ${ }^{\circledR}$ has been developed by Melchart et al as an electronic patient record named "Medical Monitoring ${ }^{\circledR}$."42 In order to develop VITERIO ${ }^{\circledR}$ tailored to the requirement of the comprehensive lifestyle intervention program IHM, the scientifically evidenced questionnaires that form the core of Health Checks 1 and 2 (see result section) had to be included into the e-Health portal. Validity and reliability were the most important criteria in the selection process of the questionnaires. All questionnaires and their application are based on clinically proven or populationbased scientific information and results.

In order to prove validity and reliability of VITERIO ${ }^{\circledR}$ in the clinical setting, we have used this tool in a randomized controlled trial on weight reduction in the TALENT study ${ }^{10,11}$ and in a prevention program in individuals with perceived stress. $^{43}$

Adherence of the participants, on the one hand, and mediation of teaching and learning contents, on the other hand, are the most important issues in the field of preventive medicine and lifestyle interventions..$^{40,41,44}$ VITERIO $^{\circledR}$ addresses both problems through the implementation of patient-centric, PMs-based programs including open records and blended learning techniques. By means of a so-called web-based training, VITERIO ${ }^{\circledR}$ offers the participant a systematic interpretation of his personal data in the framework of his individual establishment. Accordingly, VITERIO ${ }^{\circledR}$ creates an indication-specific Health Management Program for healthy participants with defined (high) risk burdens (overweight, prediabetes, prehypertension, preobesity, and preburnout) or a Disease Management Program for participants with already-established diseases (treated hypertension, type II diabetes, grade II obesity, and burnout). An individual lifestyle training program represents the fundament of reaching the aim of a healthy lifestyle. VITERIO ${ }^{\circledR}$ and the included 
"Info@zepte" offer a comprehensive spectrum of recommendations and instructions in the form of audio files, video files, and PDF files, structured according to indication, basis functions, and basis competencies. Depending on the objective, coaches or health professionals customize the content and give more detailed or more general advice in the form of individual training and therapy concepts (e.g., weight reduction or stress relief).

To ameliorate the usability of VITERIO ${ }^{\circledR}$, many checks and proofs have been necessary and will be as well in the future. Beside technical aspects, the quality of the accompanied coaches and physicians has to be guaranteed by continuously teaching and establishing a postgraduate course at the Faculty for Applied Health Science, Deggendorf.

A steering committee should assume responsibility for the whole collaboration, which will function as the main governing board. In addition, there will be two more organizational units, namely a Scientific Advisory Board and a Project Advisory Board, making recommendations toward research strategy and common policies.

Due to the large sample size collected throughout the years in VITERIO ${ }^{\circledR}$, a selection of responses to the items of PROs can also easily be used for research reason and scientific questions. CoCoNat has established a collaborative of IHM providers in different Bavarian (Germany) health resorts, recently. This network, called IHM campus, is accompanied by some researchers of different colleges and supported by health politicians as well as some sickness funds. The IHM campus has started to collect self-reported data from diverse populations of individuals, changing over various kinds of health promotion or self-management groups in chronic diseases. The user network gives suggestions to optimize usability and performance of the applications. Primary settings are communities, health tourism, companies, and medical supply clientele. The IHM campus is a for-profit organization concerning the implementation of IHM services in spa regions, clinics, practice, and doctor's offices. In terms of research activities, the network is also a nonprofit organization, ensuring that the research resources developed through the network and the results of publicly funded research become readily available to the research community.

\section{Conclusion}

In future, the network "IHM campus" will provide a statistical coordination center that offers analyses of outcomes of, e.g., operational health hazards, mainly organized by spa centers for commercial purpose. Furthermore, the network will organize a comprehensive data collection and storage and management of data. It will provide clinical studies - as already done so for the TALENT study - quality assurance programs, epidemiological studies, and adherence research and will generate item banks. ${ }^{44}$ IHM campus is determined to ensure that all our service users receive quality-controlled and equitable treatment. It is also committed to promote good relations between all sectors of the network and to serve continuous improvements in quality assurance. This includes an effective governance due to decision-making processes and data and project governance in order to have guiding principles for sharing data while protecting privacy and security. ${ }^{45,46}$ These research activities will also support evidence in Health Resort Medicine, an underestimated resource within the proving system for workplace health promotion and elderly people in Germany and worldwide, respectively. ${ }^{47}$

\section{Acknowledgments}

We thank Mr Brunner, the CEO of the company VITERIO ${ }^{\circledR}$, and his whole team for all the highly appreciated technical ssolutions according to the given concept implemented into the web portal. Furthermore, we thank Mrs Evelyn Bohnes, IHM coach, and Mrs Yanjing Wellenhofer-Li, an assistant physician, both working at the health promotion center of CoCoNat, TUM, for all their valuable practical feedbacks concerning usability and functional design of VITERIO ${ }^{\circledR}$.

Furthermore, we would like to thank all staff members of the TCM hospital, Bad Kötzting, and especially Anton Staudinger, the CEO of the hospital, for all the important support and attendance of the whole project. In addition, many thanks to all IHM coaches of participating health resorts for the successful implementation and adaptation of the software. Last but not least, we appreciate the generous funds from Erich Rothenfußer Stiftung, Munich, and all the personal engagements of both chairpersons.

Development activities at the CoCoNat, Klinikum Rechts der Isar, Technische Universität München, were supported by Erich Rothenfußer Stiftung (welfare group, patient foundation). Implementation phases were funded by the Bavarian Ministry of Health in several quality assurance and clinical research projects.

Dieter Melchart reports that he has intellectual property on the software VITERIO ${ }^{\circledR}$. However, the patent is pending, that means, it has been filed, but not issued.

\section{Author contributions}

Melchart takes full responsibility for the conceptual contents, strategy, and integrity of the medical functional work concerning lifestyle program IHM and the web-based platform 
VITERIO $^{\circledR}$. Melchart, Bachmeier, Eustachi, Gronwald, Wühr, and Wifling drafted and critically revised the manuscript. All authors contributed toward data analysis, drafting and revising the paper and agree to be accountable for all aspects of the work.

\section{Disclosure}

The authors report no conflicts of interest in this work.

\section{References}

1. Williamson DA. Fifty years of behavioral/lifestyle interventions for overweight and obesity: where have we been and where are we going? Obesity (Silver Spring). 2017;25(11):1867-1875.

2. Lambert VA, Lambert CE, Yamase H. Psychological hardiness, workplace stress and related stress reduction strategies. Nurs Health Sci. 2003;5(2):181-184.

3. van Dillen SM, Noordman J, van Dulmen S, Hiddink GJ. Setting goal and implementation intentions in consultations between practice nurses and patients with overweight or obesity in general practice. Public Health Nutr. 2015;18(16):3051-3059.

4. Taylor D, Murphy J, Ahmad M, et al. Quantified-self for obesity: physical activity behaviour sensing to improve health outcomes. Stud Health Technol Inform. 2016;220:414-416.

5. Ganiyu AB, Mabuza LH, Malete NH, Govender I, Ogunbanjo GA. Non-adherence to diet and exercise recommendations amongst patients with type 2 diabetes mellitus attending Extension II Clinic in Botswana. Afr J Prim Health Care Fam Med. 2013;5(1):457.

6. Mumu SJ, Saleh F, Ara F, Afnan F, Ali L. Non-adherence to life-style modification and its factors among type 2 diabetic patients. Indian $J$ Public Health. 2014;58(1):40-44.

7. Jensen MD, Ryan DH, Apovian CM, et al. 2013 AHA/ACC/TOS guideline for the management of overweight and obesity in adults: a report of the American College of Cardiology/American Heart Association Task Force on Practice Guidelines and the Obesity Society. Circulation. 2014;129(25 Suppl 2):S102-S138.

8. Melchart D, Eustachi A, Wellenhofer-Li Y, Doerfler W, Bohnes E. Individual health management - a comprehensive lifestyle counselling programme for health promotion, disease prevention and patient education. Forsch Komplementmed. 2016;23(1):30-35.

9. Means B, Toyama Y, Murphy R, Bakia M. The effectiveness of online and blended learning: a meta-analysis of the empirical literature. Teach Coll Rec. 2013;115(3):1-47.

10. Melchart D, Doerfler W, Eustachi A, Wellenhofer-LiY, Weidenhammer W. The talent study: a multicentre randomized controlled trial assessing the impact of a 'tailored lifestyle self-management intervention' (talent) on weight reduction. BMC Obes. 2015;2:38.

11. Melchart D, Low P, Wuhr E, Kehl V, Weidenhammer W. Effects of a tailored lifestyle self-management intervention (TALENT) study on weight reduction: a randomized controlled trial. Diabetes Metab Syndr Obes. 2017;10:235-245.

12. Berking M. Training emotionaler Kompetenzen. Berlin: Springer; 2015.

13. Ellis A. Rational Emotive Behavior Therapy: It Works for Me - It Can Work for You. Westminster, MD: Prometheus Books; 2004.

14. Parikh NI, Pencina MJ, Wang TJ, et al. A risk score for predicting near-term incidence of hypertension: the Framingham Heart Study. Ann Intern Med. 2008;148(2):102-110.

15. Lindstrom J, Tuomilehto J. The diabetes risk score: a practical tool to predict type 2 diabetes risk. Diabetes Care. 2003;26(3):725-731.

16. Pines A, Kafry D, Aronson E. Burnout: From Tedium to Personal Growth. New York: The Free Press; 1981.

17. Kivimaki M, Batty GD, Singh-Manoux A, et al. Validating the Framingham Hypertension Risk Score: results from the Whitehall II study. Hypertension. 2009;54(3):496-501.
18. Saaristo T, Peltonen M, Lindstrom J, et al. Cross-sectional evaluation of the Finnish Diabetes Risk Score: a tool to identify undetected type 2 diabetes, abnormal glucose tolerance and metabolic syndrome. Diab Vasc Dis Res. 2005;2(2):67-72.

19. Henrich G, Herschbach P. Questions on Life Satisfaction (FLZM) - a short questionnaire for assessing subjective quality of life. Europ $J$ Psychol Assessment. 2000;16:150-159.

20. Primack BA. The WHO-5 Wellbeing Index performed the best in screening for depression in primary care. ACP J Club. 2003;139(2):48.

21. Folker H, Folker AP. WHO-5 som et simpelt instrument til måling af livskvalitet i den daglige klinik. [WHO-5 as a simple method for measuring quality of life in daily psychiatric clinics]. Ugeskr Laeger. 2008;170(10):830-834. Danish.

22. Scholler G, Fliege H, Klapp BF. Fragebogen zu selbstwirksamkeit, optimismus und pessimismus: restrukturierung, itemselektion und validierung eines instruments an untersuchungen klinischer stichproben. Psychother Psychosom Med Psychol. 1999;49(8):275-283.

23. Antonovsky A. The sense of coherence as a determinant of health. In: Beattie A, Gott M, Jones L, Sidell M, editors. Health and Wellbeing: A Reader. Basingstoke: Macmillan/Open University; 1993:202-214.

24. Levenstein S, Prantera C, Varvo V, et al. Development of the Perceived Stress Questionnaire: a new tool for psychosomatic research. J Psychosom Res. 1993;37(1):19-32.

25. Fliege H, Rose M, Arck P, et al. The Perceived Stress Questionnaire (PSQ) reconsidered: validation and reference values from different clinical and healthy adult samples. Psychosom Med. 2005;67(1): $78-88$.

26. Pomerleau CS, Majchrzak MJ, Pomerleau OF. Nicotine dependence and the Fagerstrom Tolerance Questionnaire: a brief review. J Subst Abuse. 1989;1(4):471-477.

27. Sherbourne CD, Stewart AL. The MOS social support survey. Soc Sci Med. 1991;32(6):705-714.

28. Costa Requena G, Salamero M, Gil F. Validación del cuestionario MOS-SSS de apoyo social en pacientes con cáncer. [Validity of the questionnaire MOS-SSS of social support in neoplastic patients]. Med Clin (Barc). 2007;128(18):687-691. Spanish.

29. Ware JE Jr, Sherbourne CD. The MOS 36-item short-form health survey (SF-36). I. Conceptual framework and item selection. Med Care. 1992;30(6):473-483.

30. McHorney CA, Ware JE Jr, Lu JF, Sherbourne CD. The MOS 36-item Short-Form Health Survey (SF-36): III. Tests of data quality, scaling assumptions, and reliability across diverse patient groups. Med Care. 1994;32(1):40-66.

31. Assmann G, Schulte H. The Prospective Cardiovascular Munster (PROCAM) study: prevalence of hyperlipidemia in persons with hypertension and/or diabetes mellitus and the relationship to coronary heart disease. Am Heart J. 1988;116(6 Pt 2):1713-1724.

32. Kari JT, Pehkonen J, Hirvensalo M, et al. Income and physical activity among adults: evidence from self-reported and pedometer-based physical activity measurements. PLoS One. 2015;10(8):e0135651.

33. Backholer K, Freak-Poli R, Peeters A. Daily step-count and change in waist circumference during a workplace pedometer program. Open $J$ Prev Med. 2012;2(2):249-256.

34. ATS Committee on Proficiency Standards for Clinical Pulmonary Function Laboratories. ATS statement: guidelines for the six-minute walk test. Am J Respir Crit Care Med. 2002;166(1):111-117.

35. Borg GA. Psychophysical bases of perceived exertion. Med Sci Sports Exerc. 1982;14(5):377-381.

36. Steinbrook R. Personally controlled online health data - the next big thing in medical care? N Engl J Med. 2008;358(16):1653-1656.

37. Slevin ML, Plant H, Lynch D, Drinkwater J, Gregory WM. Who should measure quality of life, the doctor or the patient? Br J Cancer. 1988;57(1):109-112.

38. Munoz Obino KF, Aguiar Pereira C, Caron-Lienert RS. Coaching and barriers to weight loss: an integrative review. Diabetes Metab Syndr Obes. 2016;10:1-11. 
39. Hutchesson MJ, Rollo ME, Krukowski R, et al. eHealth interventions for the prevention and treatment of overweight and obesity in adults: a systematic review with meta-analysis. Obes Rev. 2015;16(5): 376-392.

40. Jankowska-Polanska B, Chudiak A, Uchmanowicz I, Dudek K, Mazur G. Selected factors affecting adherence in the pharmacological treatment of arterial hypertension. Patient Prefer Adherence. 2017;11: 363-371.

41. Tibebu A, Mengistu D, Negesa L. Adherence to recommended lifestyle modifications and factors associated for hypertensive patients attending chronic follow-up units of selected public hospitals in Addis Ababa, Ethiopia. Patient Prefer Adherence. 2017;11:323-330.

42. Melchart D, Wichmann B, Polonius D, Saller R. Implementierung und Erprobung einer multifunktionalen elektronischen Patientenakte für Routine und Evaluation der Patientenversorgung. Praxis. 2001;90:1587-1593.
43. Melchart D, Wühr E, Doerfler W, Eustachi A, Wellenhofer-Li Y, Weidenhammer W. Preliminary outcome data of a Sino-EuropeanPrevention-Program (SEPP) in individual with perceived stress. J Prev Med Healthc. 2017;1(1):1-7.

44. Taylor RW, Roy M, Jospe MR, et al. Determining how best to support overweight adults to adhere to lifestyle change: protocol for the SWIFT study. BMC Public Health. 2015;15:861.

45. Bensing JM, Caris-Verhallen WM, Dekker J, Delnoij DM, Groenewegen PP. Doing the right thing and doing it right: toward a framework for assessing the policy relevance of health services research. Int JTechnol Assess Health Care. 2003;19(4):604-612.

46. Mayer-Schonberger V. Big Data for cardiology: novel discovery? Eur Heart J. 2016;37(12):996-1001.

47. Stier-Jarmer M, Kus S, Frisch D, Sabariego C, Schuh A. Health resort medicine in non-musculoskeletal disorders: is there evidence of its effectiveness? Int J Biometeorol. 2015;59(10):1523-1544.
Patient Related Outcome Measures

\section{Publish your work in this journal}

Patient Related Outcome Measures is an international, peer-reviewed, open access journal focusing on treatment outcomes specifically relevant to patients. All aspects of patient care are addressed within the journal and practitioners from all disciplines are invited to submit their work as well as healthcare researchers and patient support groups.
Dovepress

The journal is included in PubMed. The manuscript management system is completely online and includes a very quick and fair peer-review system. Visit http://www.dovepress.com/testimonials.php to read real quotes from published authors. 